\title{
Territorial transformation and water utilization: hydrological planning scenarios in the Segura river basin
}

\author{
A. Grindlay ${ }^{1}$, M. Zamorano ${ }^{2}$, M. I. Rodríguez ${ }^{1}$, E. Molero ${ }^{1}$ \\ \& M. A. Urrea ${ }^{3}$ \\ ${ }^{1}$ Urban and Spatial Planning Laboratory, University of Granada, Spain \\ ${ }^{2}$ Department of Civil Engineering, Section of Environmental Technology, \\ University of Granada, Spain \\ ${ }^{3}$ Hydrological Planning Board, Segura River Basin Auth., Murcia, Spain
}

\begin{abstract}
Considering the particular climatic and water conditions of this semiarid region in southeast Spain, the hydrographic basin of the Segura river is a very dynamic territory. This is reflected in the important spatial transformation that it has undergone in the second half of the $20^{\text {th }}$ century, entailing the expansion of irrigated surfaces as well as extension of urban areas, as well as the proliferation of golf courses over the past two decades. The progressive increase in demand owing to such intensive use of water resources is linked to a supply-oriented hydraulic policy, with major infrastructural actions that contribute to a substantial water deficit, as registered by the latest hydrological plan. Meanwhile, the urban supply of water was decisively resolved to make sources of water supply available; recently, thanks to the new desalinization resources and the ensuing guarantee of supply, water is not a limiting factor for urban development along the coast, as reflected in the local urban plan. The current implementation of the European Water Framework Directive stands as a radical change in the orientation of hydraulic policy. Strict environmental supervision, which translates as the maintenance of ecological flows and the restriction of uses, will give rise to planning scenarios within the new hydrological context that maintain a water deficit only with regard to agricultural consumption. Otherwise, in light of the new measures, sustainable water scenarios can be envisioned.
\end{abstract}

Keywords: spatial transformation, hydrological and territorial planning, WFD implementation, planning scenarios, sustainability. 


\section{Introduction}

The territory of the Segura river basin is a very dynamic space, which has undergone major transformational processes, above all within the past 50 years and along the shoreline. Despite its hydrological limitations, yet because of its particular natural conditions as well, these important processes of spatial transformation have been linked to uses calling for great water demands: agriculture [1] and tourism [2]. This has given rise to a structural water deficit with an unsustainable trend [1].

The application of the Water Framework Directive (WFD) (2000/60/CE) involves a complete change in orientation of water policy in Spain. The supply integrates management of demand, with strict environmental objectives. It is also necessary to attend to the specific conditions of different regions, such as the semi-arid river basins [3]. At present, the new hydrological plan under elaboration in accordance with the WFD specifications requires efforts dedicated to achieving a good state of all water masses and their sustainable use, as well as enforcement of the Water Law still in force, for "the adequate satisfaction of demands for different uses." Thus, new planning scenarios will result, in which the demands for urban/industrial supply must be guaranteed along with future development. The restrictions of the environmental flows will, however, imply a relevant water deficit in regard to agricultural demands.

This paper presents these processes of spatial transformation and the water demands they entail, whether related with the extension of irrigated areas or the proliferation of golf courses near tourist resorts. The new hydrological planning scenarios deriving from implementation of the WFD are discussed as well.

\section{Territorial transformation and water utilization in the Segura river basin}

The main territorial characteristic of the peninsular region of Southeast Spain, where the Segura river basin is situated, is aridness [3,4], with important problems of erosion and desertification [5], associated in turn with an inadequate and unsustainable treatment of water and soil in the agricultural terrains [6].

The benign climate, with high solar radiation and luminosity, together with the good agronomic quality of the soil, have made this zone a traditionally very productive one, affording high economic yields in agricultural [1]. At the same time, considerable difficulty lies in the agricultural development of the zone giving its limited water resources, because of scarce and irregular precipitation over space and time. This led to a very early need for the construction of major hydraulic works, with infrastructures for the catchment, storage and distribution of water [7]. Moreover, the natural landscape of the zone was to favour another model of development, alongside agriculture, and likewise very dependent upon water: urban development for residents and tourists, principally along the coast and near the metropolitan areas. For this reason, water demand has surpassed the limited availability of this resource for decades. As a consequence, the so-called 
"water deficit" is one of the great paradigms characterizing the territory around the Segura river [8].

\subsection{The expansion of the surfaces of irrigation and the growth of the water demands for irrigation}

The extraordinary lack of proportion in productivity and profitability between the dry areas and irrigated lands of this zone tend to cause a natural "tension toward transformation" in the irrigated surfaces [9]. The historic and consolidated process of irrigated lands growth began with those traditionally known as irrigated land [1]; the perimeters of the alluvial vegas or fertile plains would correspond to this denomination. Throughout the $20^{\text {th }}$ century, with the application of motors to pump water, the irrigated areas were extended beyond the floodplains, a process generating new surfaces that relied heavily on groundwater, with aquifers consequently suffering a serious process of overexploitation $[10,11]$.

Establishing the evolution of these surfaces was done using data from the last hydrological plan [10] as opposed to anterior plans (1933, 1941, 1953, 1968, 1974, 1980) and the Annex of Agrarian Demand. In addition, analysis of the dynamics of the uses of the soil, evaluated on the basis of three images from the Landsat Satellite, corresponding to the years 1984, 1991 and 2005, were consulted to quantify the changes in land use, with special attention to the use of irrigation. These data were completed with information proceeding from a similar teledetection study carried out by Spain's General Water Director of the Ministry of the Environment (Dirección General del Agua, Ministerio de Medio Ambiente), who reported on the evolution of the net surface irrigated in the years 1984, 1990, 2000 and 2004 [12]. We must underline the distinction between gross and net hectares, the former referring to the total perimeter encompassing the irrigated areas in which growing are mainly developed, subtracting those surfaces areas within them that are not productive, as well as accounting for the rotations of the different crops, which leaves us with the figure for net surfaces.

One sees in their evolution (Figure 1) that there is a great increase in the gross surfaces between the 1950's and 60's, associated with the finalization of hydraulic works in the basin area, which provided a high level of regulation (over $80 \%$ of the natural flow); a great increase was also experimented between the 1970's and 80's, linked to expectations generated by the huge diversion from the headwaters of the Tagus and Segura river basins. In terms of net hectares, we see a certain stability in these surfaces throughout the general regulatory process (around 100,000 ha) and the important expansion in the decade of the eighties, in the stage of development associated with the diversion; in the nineties this expansion became stable in the face of the limited resources provided by the headwaters of the Tagus-Segura transfer and the scarcity caused by the drought periods of that decade. The year 2004 marks the maximum irrigated surface, with high availability of resources coinciding with the recorded extension of 251.121 ha [13]. Similar growth processes of irrigated areas have been confirmed in other nearby coastal areas, such as in Granada [14] or the neighbouring basin of the Guadalquivir. 


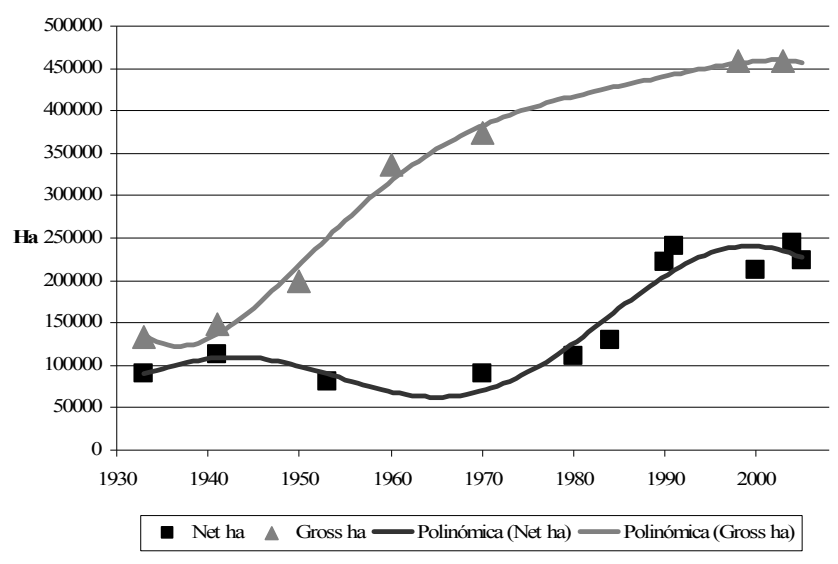

Figure 1: Evolution of the irrigation surfaces.

In accordance with the previous Hydrological Plan (1998), agricultural demands were estimated at $1660 \mathrm{hm}^{3} /$ year; at present, in the face of the new Plan, the demands have increased slightly, amounting to $1662 \mathrm{hm}^{3} /$ year [13].

\subsection{Urban development and the complex urban water supply system in the basin}

The other major process transforming this territory, and accompanied by an appreciable demand for water, is the urban development taking place in the basin. To study these transformations, the most representative cities were selected, in order to verify their urbanization dynamics. The urban perimeters of the cartographic history were determined for the first period (the 1930's), and viewed using aerial photographs for the years 1956, 1988, 1997 and 2002, to observe the evolution of the area. In addition, the metropolitan realms of Murcia, Cartagena and Lorca, were studied in detail, along with their process of suburban dispersion and industrial development.

From the quantification of the urban land surfaces in the different stages and zones of the basin, the evolution of the global surfaces of urban land were determined. This shows how the metropolitan areas of the fertile plain of Murcia have developed parallel with shoreline development in more recent times, revealing that the positive territorial dynamics of their development are very similar and of similar intensity. On the other hand, the traditional stagnation of the headwater areas is apparent.

This outstanding urban growth along coastal areas has been made manifest in other studies. According to the European Environmental Agency, the urbanization of coastal Europe shows that the highest increase in artificial surfaces (identified with urbanization) between 1990 and 2000 took place in Ireland, Spain and Portugal, with the Western Mediterranean area ranking first in these transformations. In addition, the growth of urbanization in this period was 30 percent faster in coastal areas than in inland areas, with the highest rates of increase (25-30 percent) found in Mediterranean Spain [15]. 
The teledetection techniques as applied to this particular study showed how the basin is, indeed, a very dynamic territory, with percentages of change over $50 \%$ in the periods analysed (1984-1991; 1991-2005; 1984-2005). Both the intensive agricultural activity (greenhouses) and tourism have meant the transformation, between 1984 and 2005 , of $7.61 \%$ of the basin surface. Urban supply throughout this river basin, plagued by serious deficiencies in the first half of the 20th century, was gradually resolved by the Mancomunidad de los Canales del Taibilla (MCT), the only state hydraulic organism in Spain, exclusively in charge of supplying potable water above ground to the populations of the area. It was to develop its activity in a geographic area that took in the vast majority of the municipalities located in the Segura river basin (supplying nearly $90 \%$ of these inhabitants) and six along the shores of the nearby Jucar river basin. Since 1945 this organism has progressively supplied the bulk of the populations in the basin by means of a great infrastructural project involving water conducts and deposits. In order to ensure increase in supply to the populations joining the system, the MCT had to resort to different sources. After the first twenty years of its existence, the flows proceeding from the river Taibilla were insufficient, and water had to be taken from the Segura river. In the 1980 's the waters of the Tagus-Segura Transfer, arrived, which from then on would be the main resource of the system, providing more than $60 \%$ of total volume, and guaranteeing supply, in view of the descent in flow of the rivers Segura and Taibilla. This period coincides with the greatest demand for water from the urban areas of Murcia and Alicante, and from the coast, where the implantation of homes and resorts came into full expansion. The gross urban demand was estimated in the Plan Hidrológico (1998) at $217 \mathrm{hm}^{3} /$ year, and the industrial demands at $49 \mathrm{hm}^{3} /$ year [10]; in the period 1998-2006, consumption has evolved within provisions [13].

In more recent years, however, in view of the structural scarcity of the basin and the impossibility of executing another major diversion of flow from the river Ebro, as was proposed by the national hydrological plan of 2001, the nationwide Programa A.G.U.A. (Actuaciones para la Gestión y Utilización del Agua, R.D.L. $2 / 2004$ ) opted for the massive desalinization of seawater as a solution for supply, given the technical-environmental advances and the continued reduction in the costs of producing desalinized water [16]. In this sense, the MCT has built or is building four plants, and participates as a user in another three, for a future total capacity of $181 \mathrm{hm}^{3}$. Moreover, new connections are being developed between these centres of production and the major areas of consumption (Murcia and Cartagena) to optimize the functioning of the system of supply.

Currently the MCT has a complex hydraulic system to supply a stable population of approximately 2.3 million inhabitants, which in the summer season surpasses 3 million. Notwithstanding, given the savings achieved, the reutilization and the greater efficiency in supply, the demands are currently estimated at around $200 \mathrm{hm}^{3} /$ year, and industrial demands at $46 \mathrm{hm}^{3} /$ year [13].

The Figure 2 represents the process of expansion of the urban surfaces in the Segura river basin, together with the growth in water consumption by the MCT. 


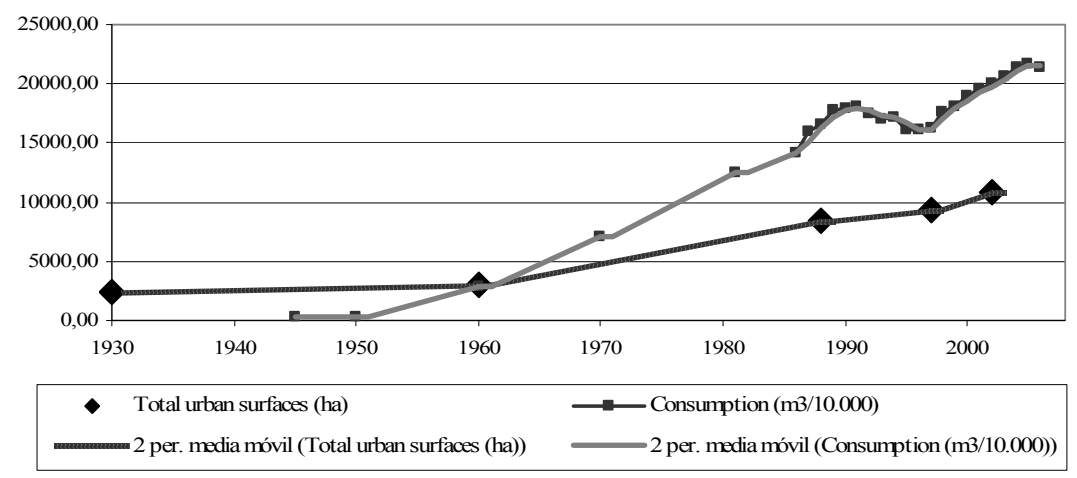

Figure 2: $\quad$ Evolution of urbanized land in the basin and water consumption by the MCT.

One particular case of urban development is the proliferation of golf courses in the basin, which has come to complement the traditional tourism of "sun and sea" with "golf + resort" type facilities [2]. These are not located, like the above, mainly in the stretch along the coast, but rather extend throughout the basin territory. To date, 38 golf courses have been approved, 25 of which are already open, and 13 others under construction; yet petitions have been presented for the development of another 35 courses. A similar model can be found in nearby coastal zones such as the Costa del Sol, Malaga Province, with 73 golf courses. The water consumed comes in some cases from modifications of use in old irrigation concessions, or from wells, but the housing developments are connected to these supply networks, so that supply is considered as urban demand of second use, and watering is approved by the reutilization of purified urban wastewater. The current demand of $13.6 \mathrm{hm}^{3}$ will double by 2015 [13].

\section{WFD application: current hydrological planning scenarios and territorial transformation}

For some decades now, emphasis has been placed on the need for coordination and integration between hydrological planning and territorial planning, and just recently different approaches and models for integrated management have been proposed $[17,18]$. However, most spatial transformations have taken place beyond any territorial or hydrological planning, leading to the serious water difficulties suffered in this territory. For this reason, there is an urgent need for correct territorial and urban planning so that growth and development to not overtake the availability of water resources [19].

As in other European countries, in Spain, hydrological planning, with its own spatial realm in the hydrographic basis, will be state-run [20]. Yet it will develop from the decentralised basin organisms, such as the historic Confederaciones Hidrográficas (river basin authorities) going back to the 1920 's. There have also been, in terms of competences, a traditional separation between this and 
territorial planning [18] which, like urban planning, would have a municipal administrative-spatial realm of action, and would come under the umbrella of Autonomous Community competences.

Only recently was the territorial planning of the basin by the regional governments approached, with reference, both for the Region of Murcia and in the Community of Valencia, to the coastal region, through with the "Directives and Plan of Territorial Ordering of the Coast" (2004) of Murcia, and the "Plan of Territorial Action of the Vega Baja (Alicante)" (2005). Thus, what we need is an instrument of territorial planning, in close coordination with the territorial planning of the neighbouring regions and with the hydrological planning now under elaboration.

Urban development is regulated by its corresponding plans, with important previsions for development, as is clear in the "Study of updating demands to be attended to by the MCT on the horizon of the Hydrological Plan (2005)", whose objective was the determination of demands in the short-, medium- and longterm, using three scenarios: that provided by a classical analysis in terms of the foreseen population, of a specific analysis taking into account both future homes foreseen by the urban plan in vigour (bearing in mind the high seasonability of tourism), and an analysis of trend of these homes with respect to the current situation. The urban plan in existence considered a level of development that gave rise to a horizon of demands far above those estimated with the demographic and tendential prognoses. A final prognosis of future demand was put forth that was based on the tendency analysis, amended by the planning and the demographic analysis [21]. This study is held up for establishing the urban industrial and tourism demands under current hydrological planning in the basin, amending their results in view of posterior reports [16].

The implementation of the WFD in each one of the European territorial contexts will have specific particularities [22], especially in semi-arid settings such as the Segura river basin, owing to difficulties in establishing the conditions of reference [17]. Likewise, in this territory a sustainable water management has been considered as the principal means of fighting desertification, through the reduction of water demands, the control of expansion of irrigated areas, the sustainable management of the aquifers, etc. [6].

Presently under elaboration is a new hydrological plan in agreement with the WFD. To this end, a document known as the "Scheme of Important Topics" (Esquema de Temas Importantes, or ETI), gives priority to the most relevant matters to be achieved by the year 2015 .

Regarding the achievement of environmental objectives, deserving mention here is the recognition of the environmental degradation taking place in the absence of a regime of ecological flows, the anthropic affection of the shorelines of rivers and marshes, and the overexploitation of aquifers. The first of these problems entails the greatest difficulty in its delimitations. It is also one of the elements of greatest social interest because it is a priority legal requirement over most of the uses of water in the basin area, except for supply. For this reason it is considered a restriction to the system of exploitation, reducing the limited availability of water fundamentally for irrigation. 
With respect to the objective of satisfying demands with the adequate guarantees for the different uses, we should stress that urban/industrial supply has not been included specifically as an important topic, because the measures undertaken or underway will guarantee - in the short, medium and long terms adequate satisfaction of demands by means of the disposition of the surface waters of the Taibilla river and those corresponding to the Tagus-Segura Transfer, in addition to those proceeding from the significant set of desalinization plants constructed (five), or under construction (six), in addition to amplification of the existing ones, with a future total capacity of $181 \mathrm{hm}^{3}$.

Special attention, however, is addressed to the difficulties in satisfying water demands for agrarian purposes, due to the decreasing amount of water available in the basin on the whole, due to the reduction of natural contributions (from the headwaters of the Segura and Tagus rivers) affecting the availability for agricultural uses. The hydrological series 1980-2005, applied to estimate the reserves under the new Instruction of Hydrological Planning (2007), presents a considerable drop in the regulated available resources in headwater areas; consequently additional deficits beyond those contemplated in the planning in force and based on the data series 1940-1990, have been produced. This presented in its scenarios (1998-2008) a general deficit of $460 \mathrm{hm}^{3} /$ year. Nonetheless the agricultural demand will be reduced in future to $1550 \mathrm{hm}^{3} /$ year thanks to the modernization of irrigation contemplated in the A.G.U.A. program.

Once the balances of the unique system of exploitation have been updated, with the functioning of the A.G.U.A. program guidelines (horizons 2009 and 2015-2027), and under the model of the system of exploitation of the basin used in the studies developed for the elaboration of the Hydrological Plan, there is still a substantial final year on year average deficit in the demarcation for the year 2015, estimated according to the different scenarios considered in the ETI at somewhere between $41 \mathrm{hm} 3 /$ year and $371 \mathrm{hm} 3 /$ year [13].

In short, considering the savings, new resources and greater efficiency in the use of the water, the balances have improved with respect to the previsions of the previous Hydrological Plan (1998). It has been possible thanks to the reduction of the resources assigned only to agriculture, toward a more sustainable horizon according to the WFD.

\section{Conclusions}

The arid Segura River Basin has undergone an accelerated and intense process of territorial transformation based on two models of development, both highly dependent upon water: agriculture and urban development. Together with the drought phenomena, the chronic situation of water deficit has progressively worsened. Alongside this evolution, we see insufficient progress in the regional competences in the area of territorial planning. Except for the more dynamic realm of the coast, where indeed the greatest rates of growth are seen, the massive application of desalinization has meant that water is not a limiting factor for development in this area, reflected in the proliferation of golf courses; and that the demands for urban/industrial supply are guaranteed in the long term. 
Despite the traditional division of competences between the two areas of planning, the new hydrological plan stemming from the WFD foments a relative integration with urban-territorial planning, especially regarding demands and environmental objectives. After the determination of ecological flows and a process of coordinated decision-making process, considering environmental, social and economic cost, one of the greatest obstacles now faced in its implementation resides in the fact that the shortage-producing agricultural demands in the basin may be covered. Finally, with the new measures for savings, the new resources and the greater efficiency in the use of water, the revised hydrological plan creates horizons that are more sustainable in the context of the WFD.

\section{Acknowledgements}

This research has been funded by the Spanish "Dirección General del Agua del Ministerio de Medio Ambiente" by a project untitled "Water, Engineering and Territory: The transformation of Segura river basin by hydraulic engineering". Also this work has been supported in part by the project P07-TIC-02913 Consejería de Innovación, Ciencia y Educación of the Autonomous Regional Government of Andalusia, untitled "Intelligent system for the environmental impact assessment of human activities (SINTEIA)".

\section{References}

[1] Martínez-Fernández, J., Esteve-Selma, M.A. \& Calvo-Sendín, J.F. Environmental and Socioeconomic Interactions in the Evolution of Traditional Irrigated Lands: A Dynamic System Model. Human Ecology, 28, pp. 279-299, 2000.

[2] Rico-Amorós, A.M., Olcina-Cantos, J, \& Sauri, D. Tourist land use patterns and water demand: Evidence from the Western Mediterranean. Land Use Policy, 26, pp. 493-501, 2009.

[3] Thornes, J. B. \& Rowntree, K. M. Integrated catchment management in semiarid environments in the context of the European Water Framework Directive. Land Degradation \& Development, 17, pp. 355-364, 2006.

[4] Vidal-Abarca, M.R., Montes. C., Suárez, M.L. \& Ramírez-Díaz, L. An Approach to the Ecological Characterization of Arid and Semiarid Basins. GeoJournal, 26, pp. 335-340, 1992.

[5] Oñate, J.J. \& Peco, B. Policy impact on desertification: stakeholders' perceptions in southeast Spain. Land Use Policy, 22, pp. 103-114, 2005

[6] Martínez-Fernández, J. \& Esteve-Selma, M.A. A critical view of the desertification debate in southeastern Spain. Land Degradation \& Development, 16, pp. 529-539, 2005.

[7] Gómez Ordóñez, J.L. y Grindlay Moreno, A.L. (dirs.) Agua, Ingeniería y Territorio: La Transformación de la Cuenca del río Segura por la Ingeniería Hidráulica. Confederación Hidrográfica del Segura, Murcia, 2008. 
[8] Morales Gil, A. Agua y territorio en la Región de Murcia. Fundación Centro de Estudios Históricos e Investigaciones Locales. Murcia, 2001.

[9] Ministerio de Medio Ambiente. Libro Blanco del Agua. Secretaría de Estado de Aguas y Costas, Madrid, 2000. http://hispagua.cedex.es/documentacion/documentos/1_b/1_b.php?localizaci on=Libro $\% 20$ Blanco $\% 20 \mathrm{del} \% 20$ Agua

[10] Confederación Hidrográfica del Segura (CHS). Plan Hidrológico de la Cuenca del Segura, Memoria. Ministerio de Medioambiente, 1998. http://www.chsegura.es/chs/planificacionydma/plandecuenca/documentosc ompletos/

[11] Confederación Hidrográfica del Segura (CHS). Plan Especial ante situaciones de alerta y eventual sequía de la cuenca del Segura, 2007 http://www.chsegura.es/chs/cuenca/sequias/pes/EEAPES.html

[12] Urrea Mallebrera, M. A. El Plan Hidrológico de la Demarcación Hidrográfica del Segura: un nuevo reto de Gestión Integrada de los Recursos Hídricos. Ingeniería y Territorio, 80, pp. 72-81, 2007.

[13] Confederación Hidrográfica del Segura (CHS). Esquema Provisional de Temas Importantes (ETI). Demarcación Hidrográfica del Segura, 2008. http://www.chsegura.es/chs/planificacionydma/planificacion/index.html\#eti

[14] Rodríguez Rojas. La Planificación Territorial del Agua en la Región del Guadalfeo. Tesis Doctoral, Universidad de Granada, 2008.

[15] European Environment Agency (EEA). The Changing Face of Europe's Coastal Areas. EEA Report No 6/2006. Urban Sprawl in Europe. The Ignored Challenge. EEA Report No 10/2006. Copenhagen.

[16] Urrea Mallebrera, M.A. El abastecimiento de agua potable en la nueva planificación hidrológica en la cuenca del Segura. Actas del I Congreso de Urbanismo y Ordenación del Territorio. CICCP, 2008.

[17] Thornes, J.B. \& Rowntree, K.M. Integrated catchment management in semiarid environments in the context of the European Water Framework Directive. Land Degradation \& Development, 17, pp. 355-364

[18] Woltjer, J. \& Al, N. Integrating Water Management and Spatial Planning. Journal of the American Planning Association, 73, pp. 211 - 222, 2007.

[19] Greenpeace. El negocio del agua en la cuenca del Segura. 130 pp. 2007. http://www.greenpeace.org/raw/content/espana/reports/el-negocio-delagua-en-la-cuen.pdf

[20] Dirksen, W. Water Management Structures in Europe. Irrigation and Drainage, 51, pp. 199-211, 2002.

[21] Ministerio de Medio Ambiente, DGA. Mancomunidad de los Canales del Taibilla. Estudio de actualización de las demandas a atender por la MCT en el horizonte del Plan Hidrológico. Aquagest Levante, 2005.

[22] White, I. \& Howe, J. Policy and Practice: Planning and the European Union water framework directive. Journal of Environmental Planning and Management, 46, pp. $621-631,2003$. 